\title{
Una Tipología de los Nuevos Habitantes del Campo: aportes para el estudio del fenómeno neorrural a partir del caso de Manizales, Colombia
}

\author{
Marlon Javier Méndez Sastoque ${ }^{1}$
}

Resumen: El artículo presentar una propuesta tipológica de los nuevos y diversos habitantes del campo, asumiendo como sustento el caso de Manizales, Colombia. Se construyó mediante el análisis de información producto de entrevistas semiestructuradas centradas en las motivaciones para migrar de la ciudad al campo y el proceso de inmersión de los migrantes al espacio social de acogida. El análisis permitió establecer cuatro tipos de nuevos habitantes del campo: a) neorrurales por atracción comparativa, b) neorrurales por atracción ético-política, c) neorrurales por atracción económico-productiva, y d) neorrurales por expulsión. Se concluye que el neorruralismo es una expresión localizada, variable en relación con el dominio o contexto de ocurrencia.

Palabras-claves: neorruralismo, ruralidades contemporáneas, integración ruralurbana, sociedades rurales.

\begin{abstract}
The paper present a typology of the new and diverse new rural residents assuming as empirical support the case study of Manizales, Colombia. The information was generated from semi-structured interviews focused on the motivations to migrate from the city to the country and the integration of migrants to host social space. The analysis allowed establishing four types of new rural people: a) neo-rural for comparative attraction, b) neo-rural for ethical-political attraction, c) neo-rural for economic-productive attraction and d) neo-rural for expulsion. It is concluded that the neoruralism is a localized expression, variable with the social context of the occurrence.
\end{abstract}

Key-words: neoruralism, contemporary ruralities, rural-urban integration, rural societies.

Clasificación JEL: R14, R23.

1. Ingeniero Agrónomo. Doctor en Desarrollo, Agricultura y Sociedad. Profesor del Departamento de Desarrollo Rural y Recursos Naturales de la Universidad de Caldas, Colombia. E-mail: marlon.mendez@ucaldas.edu.co 


\section{Introducción}

Progresivamente, la idea que asocia lo rural a la territorización de lo agrícola ha venido cediendo espacio a nuevas interpretaciones y lecturas. Hoy en día existe cierto consenso acerca de que el mundo rural va más allá de lo meramente agropecuario. Sobre esta premisa, nuevas prácticas e interacciones sociales son reconocidas como parte de ese mismo universo. En términos generales, a la tarea, otrora esencialista, de producir alimentos e insumos para la industria, se suman otras que, en conjunto, complejizan y varían el uso y la apropiación social del espacio, situación que conduce a reducir el poder explicativo de la lectura agraria/unisectorial de lo rural.

Desde la perspectiva demográfica, entre las bases para pensar un espacio rural menos unisectorial y más diversificado, será preciso considerar los cambios ocurridos en la composición poblacional de las múltiples y variadas localidades rurales.

Además de agricultores exclusivos o pluriactivos, nuevos habitantes del campo darían cuenta del cambio en la composición poblacional rural, y sobre todo de la emergencia de otras formas de aprehender y otorgar sentido a los espacios y vivencias rurales, a la luz de lo considerado por esos otros o nuevos actores. Adoptando lo anterior, sería posible plantear que estas formas alternativas de concebir y experimentar lo rural remitirán a un escenario físico y social económicamente multisectorial y socialmente heterogéneo, donde los agricultores dejarían de ser los únicos y legítimos representantes de las sociedades rurales, dando lugar a la expresión de diferentes actores. Para estos "otros rurales" -en este caso sujetos de origen urbano que por uno $\mathrm{u}$ otro motivo optaron por trasladarse al campolo rural constituiría aquel escenario físico-social sobre el cual podrían proyectar sus distintos deseos e intereses (OLIVA y CAMARERO, 2005), premisa que norteó esta investigación.

Por tanto, en un mismo espacio físico-social (en una vereda, en un pueblo o pequeño poblado rural, por ejemplo) podrían coexistir múltiples actores para quienes "lo rural" adquiriría sentidos y significados distintos. Sobre esta lectura, más que un marco estricto, física y objetivamente delimitado, el espacio rural constituiría un escenario en el cual diversos actores, bien sea grupal o individualmente, forjarían un contexto de vida afín a sus imaginarios de rural y modo de vida rural.

En este marco de transformación demográfica surgen las siguientes inquietudes: si se asume como punto de partida que los múltiples y diversos nuevos habitantes del campo conciben y se apropian diferentemente de los espacios rurales, ¿qué distintas maneras de significar y vivenciar lo rural orientarían la incursión de estos 
sujetos en los espacios físico-sociales de acogida?, ¿cuáles serían las características distintivas de los actores afines a cada una de esas formas de concebir, aprehender y experimentar lo rural, en términos de las ideas, valores y circunstancias que informaron y orientaron la decisión de desplazarse al campo?

En respuesta a lo anterior, el artículo tiene como fin presentar una propuesta tipológica para los diversos nuevos habitantes del campo fundamentado en los resultados de un estudio de caso en la zona rural del municipio de Manizales, capital del departamento de Caldas, Colombia, localidad intermedia de relieve montañoso que hace parte de los Andes y el Eje Cafetero colombiano (Figura 1).

De las 44163 hectáreas que componen el municipio, 40763 (92,3\%) corresponden a la zona rural, área subdivida en siete corregimientos, en atención a condiciones agroecológicas similares. En cuanto al uso de suelo, la mayor parte del área está dedicada a la producción de café y plátano. El $79 \%$ de los predios rurales son de pequeño tamaño (menores de cuatro hectáreas), mayoritariamente dedicados a la producción de café a pequeña escala, bajo un esquema de economía campesina que caracteriza a la región. Los predios restantes (20,8\%) son de gran extensión (110 hectáreas en promedio), más dedicados al monocultivo intensivo y tecnificado de café bajos esquemas empresariales de gestión. En términos generales, sin desconocer la presencia de otros cultivos sembrados en menor cantidad, la economía en la zona rural manizaleña gira en torno a la producción de café.

En épocas de cosecha, sobre todo en las plantaciones de elevada extensión, la gran demanda de mano de obra para la recolección manual del grano ocupa a casi la totalidad de los miembros de las familias de pequeños productores (incluyendo mujeres y jóvenes mayores de 14 años de edad). Debido a este alto requerimiento, en los meses de septiembre, octubre y noviembre (periodo correspondiente a la cosecha principal) es común que en la región cafetera escasee la mano de obra, lo que exige la búsqueda de personal en municipios vecinos y otros lugares del país (municipios de los departamentos de Antioquia, Tolima y Santander, principalmente), por lo cual durante esos mes aumenta de la población flotante en la zona rural local y regional.

Paralos pequeños productores locales, recurrir a la venta de su fuerza de trabajo constituye una actividad crucial dentro de sus estrategias de reproducción socioeconómica, hecho derivado de la dificultad de sostener a sus familias sólo con lo que ellos mismos producen en sus propios

Figura 1. Ubicación del sitio de estudio

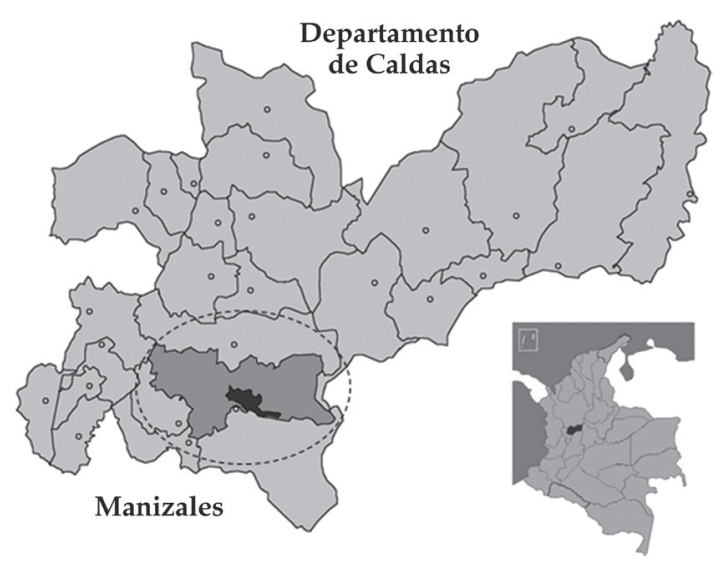

Fuente: Gobernación del departamento de Caldas. 
predios, terrenos cada vez más pequeños debido a procesos de sucesión permanente (hijos que heredan de sus padres la posesión de la tierra, provocando una continuo fraccionamiento de la propiedad).

Bajo estas circunstancias, en la medida en que los predios (debido a su mínima extensión) resultan prácticamente improductivos, algunos herederos deciden vender sus pequeñas propiedades, estando entre los compradores de lotes o terrenos, los aquí llamados neorrurales, quienes logran adquirirlos a precios mesurados. Sumado a la microfundización aludida, la resolución de vender es además estimulada por la actual crisis cafetera, escenario atribuible a la caída de las cláusulas internacionales del café, la devaluación del dólar frente al peso colombiano y la presencia nuevos problemas fitosanitarios. Es una situación compleja que hoy mantiene empobrecidos sobre todo a los pequeños productores, que a su vez suscita la sensibilidad y la solidaridad de instituciones gubernamentales, ONGs y algunos nuevos habitantes del campo.

Lo anterior implica desafíos para los entes locales y regionales que demandan herramientas para dinamizar el sector agrícola a partir de la diversificación productiva, el acceso a tecnologías, créditos y tierras, y así lograr que los productores sean competitivos y generen propuestas económicamente viables, incluyendo a los pequeños y medianos productores en las cadenas agroproductivas en las prebendas $\mathrm{y}$ facilidades otorgadas por el gobierno nacional. En Caldas operan 11 cadenas productivas: plátano, caña panelera (ambos son los segundos renglones de la economía después del café), aguacate, hortofrutícola, guadua, forestales, caucho, cacao, piscicultura, ganadera (leche y carne) y cafés especiales, oportunidades no sólo aprovechadas por los productores locales con capacidad de invertir (principalmente grandes productores), sino también por foráneos e inversionistas con o sin tradición agrícola, atraídos por los recursos disponibles, convirtiéndose algunos de ellos en nuevos habitantes del campo.
Por su parte, la belleza del paisaje y el reconocimiento de la excepcionalidad de la cultura cafetera -que ameritó la declaración del paisaje cultural cafetero colombiano como Patrimonio Cultural de la Humanidad por la UNESCO en el 2011- continúa atrayendo a turistas e interesados en vivir temporal o permanentemente allí, disfrutando de un ambiente considerado por algunos ideal y sano para el descanso y una vida apacible. Desde otro ángulo, se trata de una zona que sobrelleva el imaginario nacional de un territorio de paz y bienestar, representación sustentada, según Palacio y Cifuentes (2005), en el ingreso tardío de Caldas a los escenarios del conflicto armado, hechos que en conjunto hacen de Manizales un espacio procurado por quienes buscan tranquilidad y huyen de la violencia en sus diferentes expresiones.

Considerando estas particularidades del medio, se parte del reconocimiento de la existencia en este espacio de múltiples ruralidades, es decir, de dinámicas sociales diferenciables ocurridas en un mismo espacio físico-social rural, singularizadas a partir de la forma en que los actores que empíricamente las sustentan simbolizan ese espacio de ocurrencia, lo apropian e interactúan entre sí y con los otros, en atención a sus formas particulares de significar $\mathrm{u}$ otorgar sentido a lo rural. En este marco de diversidad donde se asume la existencia de estos nuevos habitantes del campo, actores coparticipes de la construcción del mundo rural local.

A lo largo del trabajo, con el fin de facilitar la sistematización tipológica, los términos "neorrural" y "nuevos habitantes del campo" se utilizan indistintamente, refiriéndose a aquellas personas de anterior residencia urbana que, motivados por distintas circunstancias (bien sean calificables como subjetivas $\mathrm{u}$ objetivas), conscientemente deciden mudarse al campo, en aras de forjar allí un proyecto de vida más deseable, satisfactorio o ventajoso, en relación con lo que para ellos significa vivir en la ciudad y/o el aprovechamiento de las oportunidades brindadas por los espacios sociogeográficos rurales. 
En el estudio resultó decisivo considerar las particularidades del contexto local y nacional, escenario cultural y sociopolítico distinto al de otros investigados sobre el mismo fenómeno (numerosas pesquisas referidas al contexto europeo y norteamericano). Esto exigió extender la mirada hacia formas más endógenas de apropiar y concebir lo rural, apostándole a construir una tipología, aún inacabada y susceptible de ser ampliada, que dé cuenta de lo que se podría reconocer como "neorruralismo autóctono".

Finalmente es preciso mencionar que este estudio tuvo origen en una inquietud académica y personal: la invisibililización del papel cumplido por aquellos "otros rurales" activamente participes de las dinámicas sociales rurales contemporáneas, usualmente ignorados por investigaciones especializadas. Nos referimos a estudios casi siempre concentrados en fenómenos que envuelven a unos pocos actores (productores agrícolas en sus distintas dimensiones, por lo menos para el caso colombiano) connaturalmente asumidos como protagonistas y típicos de las sociedades rurales, que desconocen la existencia de otros rurales emergentes, casi siempre considerados como secundarios o mínimamente representativos. Darles presencia y voz a los nuevos habitantes del campo o neorrurales es uno de los propósitos perseguidos por esta investigación.

\section{Metodología}

La investigación comienza en precisar y limitar los tipos de migración que en el sitio específico de estudio dan lugar a la figura de nuevos habitantes del campo o neorrurales. Considerando lo propuesto por Oberai (1989), los criterios seguidos para su determinación fueron el espacial y el residencial. De acuerdo con ello, el tipo de migración urbano-rural hallado en la fase exploratoria correspondió a aquel caracterizado por la ubicación terminante de la vivienda fija o principal en el campo, acompañado de dos posibilidades: a) de un desplazamiento diario o regular campo-ciudad-campo en función de actividades cotidianas como el trabajo y la educación, principalmente y/o b) de un situación más definitiva de abandono del espacio urbano de origen, atendiendo a razones ocupacionales o a la búsqueda de condiciones de seguridad personal y familiar. Lo anterior se hizo con base en el conocimiento previo del cambio poblacional acontecido en la zona rural del municipio de Manizales, saber obtenido de una investigación más extensa, centrada en la identificación in situ de múltiples significaciones otorgadas a lo rural, conjugado con la subsecuente aproximación preliminar con líderes locales, principalmente presidentes de las juntas de acción comunal.

El segundo paso fue identificar y contactar en el sitio de estudio a migrantes provenientes de zonas urbanas que optaron por ubicarse en distintas veredas o sublocalidades rurales del municipio, aún sin discriminar las motivaciones que los llevaron a ello. Los primeros contactos se hicieron recurriendo funcionarios de la Gerencia de Desarrollo Rural del municipio (unidad de asistencia técnica agropecuaria local), casi todos conocedores de casos relevantes, dada su relación continua con los distintos habitantes de la zona rural de Manizales. Una vez identificados los primeros informantes, siguiendo la técnica de bola de nieva, se les pidió que recomendaran a nuevos participantes. Dicha presentación permitió establecer una relación de mayor confianza con ellos, así como acceder a personas difíciles de identificar.

La recolección de datos tuvo lugar entre enero y mayo de 2012 mediante entrevistas semiestructuradas, seguidas del análisis de discurso como técnica para su tratamiento, sistematización y análisis. Acogiendo las recomendaciones expuestas por Grize (1989), con las preguntas guía se pretendió reconocer las imágenes mentales, las representaciones de experiencia rural de vida, así como las correspondencias entre estas y las prácticas cotidianas de los nuevos habitantes del campo, circunstancias mediadas por las motivaciones que los llevaron a migrar. Durante las interlocuciones se procuró comenzar con preguntas concretas, factuales y 
relacionadas con la vida cotidiana de los sujetos, para paulatinamente pasar a otras que exigieron reflexiones más abstractas, emociones y juicios de valor sobre su experiencia de vida rural (Jodelet, 2006), siempre considerando la dificultad de separar lo afectivo de lo cognitivo.

Recurriendo a las orientaciones dadas por Oliveira y Stern (1972) en relación con las migraciones internas, las preguntas guía giraron en torno a las siguientes temáticas: a) la motivación para migrar, considerando tanto las condiciones del lugar de origen (la ciudad) que motivan el proceso migratorio, como la influencia y la imagen del lugar de destino (el campo) y la incidencia de ambos en la decisión de migrar, y b) la inserción de los migrantes en el contexto social de acogida. Las entrevistas, realizadas en tono básicamente informal, se tornaron verdaderas conversaciones de naturaleza biográfica, algunas largas, otras más cortas, donde los nuevos habitantes del campo contaron abiertamente sus historias en sus propios términos.

Usando como criterio el punto de saturación, se realizaron 21 entrevistas. Cuando los temas y argumentos comenzaron a repetirse, una vez que fue posible identificar padrones simbólicos, prácticas, categorías de análisis de la realidad y visiones de mundo acerca de la decisión de migrar al campo y del modo de vida forjado posteriormente a la instalación en los lugares de acogida, se dio por finalizado el trabajo de campo. Cabe mencionar que en algunas ocasiones fue necesario retornar a las áreas de trabajo para aclarar dudas y recoger nuevos datos acerca de acontecimientos y circunstancias relevantes poco exploradas en las entrevistas.

Finalmente, una vez transcritas las entrevistas, se siguieron los siguientes pasos para codificar la información disponible: a) lectura repetitiva de los textos, b) hallazgo de objetos diferenciadores emergentes, c) detección inductiva de grupos homogéneos, d), especificación de los atributos peculiares de cada grupo homogéneo, e) análisis de características distintivas, y f) construcción/ propuesta de tipos.

\section{Resultados y discusión}

Reconocer las sociedades rurales en su condición de múltiples y heterogéneas demanda también examinar la diversidad de actores que empíricamente las sustentan. Para el caso de estudio, de ese conjunto compuesto por diferentes actores, los nuevos habitantes del campo son quienes esta vez ocupan la atención. En esta línea, lo que viene a continuación constituye una propuesta de acercamiento comprensivo al fenómeno neorrural, mediante el reconocimiento de dichos actores en su diversidad, usando como vía la clasificación por perfiles, rasgos peculiares definidos a partir de características compartidas y diferenciadoras.

\subsection{Neorrurales por atracción comparativa}

Personas para quienes habitar en el campo representa una salida al agotamiento que supone el ritmo de la vida citadina. Para muchos de ellos, vivir en el campo significa reconstituir parte de lo perdido en la ciudad. Asuntos como el anonimato, el individualismo, la artificialidad del paisaje, la sobrepoblación, la congestión vehicular, la cada vez menos disponibilidad de espacios abiertos, el predominio de relaciones basadas en intercambios comerciales, entre las más señaladas por los entrevistados, hacen parte de la inconformidad experimentada en la ciudad. En esta vía, podría plantearse que, en oposición al agite de la vida en la urbe, sensaciones de libertad, naturalidad y simplicidad serían recuperadas a partir de "la vida en el campo". El mayor contacto con la naturaleza, la posibilidad de producir parte de sus propios alimentos (aunque sea apenas simbólicamente, debido a los mínimos volúmenes obtenidos), así como el disfrute de un ambiente asumido como más saludable, simple y agradable harían parte de un nuevo y deseado estilo de vida.

En este contexto, desde una perspectiva analítica, lo rural equivaldría a un espacio propicio para materializar ideas de bienestar y cambios 
positivos en el modo de vida individual y familiar, figuraciones principalmente creadas en contraste con el estilo de vida en la ciudad y materializadas a partir de la residencia en el campo. Siguiendo este planteamiento podría decirse que, más que el contacto con el campo y la naturaleza en sí, lo que movilizaría a algunos de estos neorrurales sería la emoción proporcionada por el encuentro con "algo" que fue perdido en la ciudad, es decir, con elementos considerados ausentes de la imagen contemporánea de ciudad, aunque aún encuadrados en un halo de urbanidad (DE PAULA, 2005). Se trataría de elementos en esencia ligados a un proyecto moderno de sociedad urbana (calidad de vida, heterogeneidad, libertad, entre otros), hoy desgastados por el progreso de la misma civilización urbana.

En términos generales, se trata de profesionales liberales (arquitectos, médicos, sociólogos, agrónomos, biólogos, tanto activos como jubilados, para el caso de estudio), quienes, junto con sus hijos, diariamente se desplazan de los sitios rurales de residencia a sus lugares de trabajo y estudio en la ciudad. Para ellos, la dificultad que supone vivir en lugares alejados es compensada por el disfrute de un ambiente que les proporciones mayor calidad de vida, de acuerdo con su concepción particular de ésta. En relación con su situación económica, se trata de familias de clase media-alta que tienen resuelta, con alto grado de solvencia, su reproducción socioeconómica.

Los neorrurales por atracción comparativa se pueden subdividir en:

\subsubsection{Neorrurales integracionistas}

Personas cuyo interés y fuente de realización personal consiste en integrarse activamente a las dinámicas sociocomunitaria propias de los sitios rurales de acogida, estableciendo, hasta donde sea posible, lazos sociales sólidos entre ellos y sus nuevos congéneres rurales. En este caso, se trata de un tipo de integración social en donde la referencia para los nuevos habitantes del campo no es la sociedad urbana de origen sino lo asumido como característico de la sociedad rural o autóctona de acogida, circunstancia que da pie a la instauración de un proceso deseado y premeditadamente buscado de asimilación de lo por ellos asumido como cultura rural, acompañado de la integración a los procesos sociocomunitarios locales en cuanto camino de inmersión al nuevo ambiente.

En esta vía de asimilación cultural, para la mayoría de ellos la opción por vivir en un espacio rural demandaría adoptar, entre otras prácticas, "la vida simple de la gente del campo", "las formas amigables de relacionarse con el ambiente natural", "las relaciones armónicas con la naturaleza", "la fraternidad y la solidaridad como valores habituales de relación con los otros", formas de ser y actuar casi siempre idealizadas y correspondientes con su particular manera de representar el modo de vida rural. Analíticamente, se trataría de vivencias que podrían desembocar en la emulación parcial del "buen campesino": persona cuya conducta pública y privada muestra que posee valores, que es gentil y sana, que tiene moral, que venera a su comunidad y a su familia, que es pura, cándida, espontánea, honesta y trabajadora (FERNÁNDEZ, 2009); visión que contrasta con la que se tiene de los habitantes citadinos: contaminadores, individualistas en sus diversas acciones, calculadores y de relaciones humanas instrumentalistas.

Un elemento central ligado a la representación anteriormente descrita es la asociación realizada entre agricultura y modo rural de vida, por lo que asumir el papel de nuevo habitante de campo significa, hasta cierto punto, "tener algo de buen agricultor", propósito asociado al establecimiento de una relación directa y armónica con el entorno natural. Para varios de ellos, sus casas-fincas, además de proporcionar un medio placentero de vida (mayor contacto con la naturaleza, noches silenciosas, aire puro, espacios abiertos, entre lo más señalado), también constituyen espacios agroproductivos, usualmente sin fines comerciales, donde ejercer la agricultura es asumido como una importante práctica de inmersión en la cultura local. En términos 
S038 - Una Tipología de los Nuevos Habitantes del Campo: aportes para el estudio del fenómeno neorrural a partir del caso de Manizales, Colombia

integracionistas, sería en el proceso de "aprender a cultivar" que los nuevos habitantes del campo sin ascendencia agrícola o rural interactuarían, por lo menos inicialmente, con los habitantes originarios de las zonas rurales receptoras, generando dinámicas de integración más allá de lo meramente agrícola instrumental.

Un caso que da cuenta de lo anterior es la vinculación gradual y formal de este tipo de neorrurales en las dinámicas sociopolíticas de índole local, a partir de la asunción de cargos de representación, principalmente. Después de un tiempo de estadía en las veredas, periodo en el cual pueden aumentar y fortalecerse las relaciones de confianza y reconocimiento mutuo, varios de ellos pasan a ocupar cargos de representación en las Juntas de Acción Comunal (JAC) o en otras instancias de participación comunitaria (consejos municipales de desarrollo rural y comités ambientales locales, para el caso en estudio), procesos de acoplamiento solidario entre "originarios" y "llegados" que ahora comparten además de un mismo espacio, preocupaciones e intereses colectivos.

En esta perspectiva, para estos nuevos habitantes del campo, participar activamente de la dinámica comunitaria de la localidad en que residen, integrarse a las diferentes redes sociales existentes y contribuir con sus talentos a su fortalecimiento, constituiría el ideal de modo rural de vida, premisas en la que se sustenta su propósito integracionista.

\subsubsection{Neorrurales escapistas}

Personas que buscan posibilidad de aislarse, por lo menos durante una parte del día, de sus rutinas diarias en la ciudad, en procura de descanso y revitalización física y psíquica. Para ellos, alcanzar estos propósitos supone contar con una "serie de mínimas comodidades", expresión de los entrevistados, que amenicen su estadía y la de sus familias en sus casas de campo. Para algunos, vivir allí significa disfrutar de los beneficios del campo sin necesidad de renunciar a sus dinámicas citadinas de vida: "Vivo en el campo y trabajo en la ciudad, disfrutando de lo bueno que cada lugar ofrece". En este contexto, podría plantearse que la rusticidad de la vida en el campo sería suavizada a partir del disfrute de comodidades similares o superiores en relación a las que disponían en los sitios urbanos de origen. En la práctica, lo anterior se traduce en vivir en casas campestres dotadas de toda una serie elementos para estar a gusto según su perspectiva de confort, habitaciones que se destacan entre las otras del lugar por su arquitectura moderna y, en algunos casos, lujosa, usualmente construidas con intenciones de aislamiento del entorno vecinal circundante.

En el sentido expuesto, próximo a lo dicho por Urry (2004), podría anotarse que, para estos neorrurales, lo rural constituiría un espacio de consumo. Tranquilidad, autenticidad, descanso, paisaje campestre, aire puro, contacto con la naturaleza, bienes y sensaciones frecuentemente asumidos como perdidos o ausentes en los contextos urbanos, harían parte de la lista recursos por ellos apropiables (consumibles), disponibles en el espacio rural. Se trata de bienes hoy cada vez más escasos en el medio urbano, cuya disponibilidad en el campo haría de lo rural un espacio de compensación. Para este tipo de neorurales, la carencia de aire puro experimentada en la ciudad sería compensada residiendo en el campo; el desgaste derivado de "una dura jornada de trabajo" sería compensado al llegar a casa, mediante "el disfrute de la paz y la tranquilidad vivida en el campo", por ejemplo.

En la relación con el medio sociocomunitario, para estos neorrurales la participación en espacios de interés colectivo es limitada y queda prácticamente reducida a la asistencia ocasional a reuniones y eventos convocados por las instancias locales. En este sentido, su vivencia de lo rural es más individual y cerrada, es decir, restricta al ámbito familiar (experiencia compartida con familiares y amigos que ocasionalmente llegan de visita, por ejemplo) y experimentada de las puertas de sus casas-fincas hacia adentro (deleite con aquello construido o naturalmente disponible al interior de sus propiedades). En este caso, no 
tener interés en integrarse o participar de la vida social local es una característica frecuente.

\subsection{Neorrurales por atracción ético-política}

Personas y grupos para quienes habitar en el campo representa una forma de expresar proactivamente solidaridad con aquellos actores rurales históricamente marginados por la sociedad en general (campesinos, pequeños productores sin tierra, trabajadores agrícolas, principalmente), aún hoy caracterizados por vivir en condición de vulnerabilidad socioeconómica. Desde la perspectiva de estos neorrurales, lo rural correspondería a un espacio actualmente dominado por la mentalidad mercantil productivista, lo que obligaría a los pobladores tradicionales del campo a actuar de acuerdo con esa racionalidad y a renunciar a otras formas de relacionamiento:"nosotros no queremos un campo totalmente mercantilizado, donde las personas no son personas sino instrumentos de mercado". Es justamente la oposición a esa realidad vista como dominante lo que justifica su opción por habitar en el campo, lo cual implica tomar de iniciativa en el desarrollo de acciones creativas generadoras de cambios, haciendo prevalecer la libertad de elección sobre las imposiciones.

En coherencia con lo expuesto, analíticamente podría plantearse que lo rural equivaldría a un campo de resistencia, en donde construir formas alternativas de relaciones constituiría el principal camino de reivindicación y transformación social. En este caso, "actuar desde a dentro en aras del cambio" es lo que desde su óptica ameritaría vivir directamente el en campo.

En términos generales, se trata de académicos, profesores, profesionales en ciencias agropecuarias y de otras disciplinas, activistas, productores ecológicos, extensionistas y miembros de algunas organizaciones sociales, quienes diariamente se desplazan de los sitios rurales de residencia a los lugares de trabajo en la ciudad, cuyos hijos generalmente cursan sus estudios primarios en las escuelas rurales, o que prestan sus servicios profesionales en el mismo escenario rural en el que habitan. En cuanto al nivel de renta, corresponde a personas con ingresos medios, constituyentes de hogares de clase media profesional, vinculados como asalariados a distintas instituciones, usualmente de carácter público o no gubernamental.

Los neorrurales por atracción ético-política se pueden subdividir en:

\subsubsection{Neorrurales agroecologistas}

Personas y grupos cuyo interés consiste en contribuira reforzar (orestaurar) en las comunidades rurales de acogida valores contrarios a los de la lógica capitalista de mercado (individualismo, eficacia, competitividad, afán de lucro, materialismo, monetarización de todo tipo de intercambio, entre otros) en cuanto guías de relacionamiento con los otros y el entorno. En coherencia, valores asumidos como anti-mercantilistas (solidaridad, ayuda mutua, comunitarismo, fraternidad, espiritualidad, entre otros) informarían y orientarían la interacción de estos neorrurales con sus congéneres originarios del campo, individuos con quienes entran a compartir un mismo espacio, ahora vistos como sus pares y vecinos.

En términos contestatarios, podría plantearse que el llamado hecho por este tipo de neorrurales convocaría a recuperar algo que se supone perdido: la autonomía de las comunidades campesinas, la independencia económica, política y cultural de los pueblos, la voz de las comunidades ancestrales, el diálogo de saberes, la espiritualidad y los lazos que unen al hombre con la tierra, y la producción ecológica principalmente de alimentos. De acuerdo con lo indagado, su intención se centraría en reclamar el derecho a otra forma de ser, actuar y pensar, incitando a múltiples y diversos actores a militar a favor de la mudanza del orden dominante, a partir de la propuesta de formas alternativas de vida y productivas, visión que encarna buena parte de los valores que sustentan la propuesta de transformación agroecológica.

En el contexto descrito, la propuesta se aproximaría a la idea expuesta por Kayser (1996) 
S040 - Una Tipología de los Nuevos Habitantes del Campo: aportes para el estudio del fenómeno neorrural a partir del caso de Manizales, Colombia

acerca de la significación y experimentación de lo rural como un espacio de innovación social. En este caso, la innovación consistiría en la apuesta constructiva a un cambio en las relaciones entre individuo, naturaleza y sociedad, centrado en tomar partido sobre los desequilibrios causados por la dinámica capitalista de mercado, afirmando y practicando un activismo crítico en contramano de esta tendencia socioeconómica predominante.

Desde la perspectiva productiva, críticos del modelo basado en la aplicación de insumos industriales en los procesos productivos, proponen la agricultura ecológica como camino de "renaturalización" y "desartificialización" de la actividad agrícola actual, expresiones usadas por los neorrurales locales para significar su distanciamiento tecnológico y político de dicha fuerza dominante. En este escenario, en cuanto actividad básica para la sobrevivencia humana, la agricultura sería apropiada como actividad conectoradeloshombresconsumediofísicodevida y de la gente del campo con el resto de la sociedad consumidora de alimentos. Según esta postura, hacer visibles las interdependencias existentes entre quienes producen y quienes consumen, a su vez disminuyendo las intermediaciones que invisibilizan estas conexiones directas, conduciría, vía reconocimiento y valoración de la labor alimentaria y conservacionista de las gentes del campo, a establecer un modelo socioproductivo ecológicamente apropiado, socialmente más justo y económicamente viable, pretensión totalmente coherentes con su forma de significar y experimentar el modo de vida rural.

\subsubsection{Neorrurales altruistas}

Personas y grupos motivados por ayudar a "los más necesitados", en este caso a campesinos y otros miembros de las comunidades rurales en condición de vulnerabilidad socioeconómica, poniendo a su servicio sus conocimientos y experticias en aras de generar mayor bienestar social. Desde esta perspectiva, para ellos el medio rural representa un espacio físico-social apto para la realización profesional, en donde la convicción de "trabajar para y con la gente del campo" -expresión recurrentemente usada por los entrevistados- sustentaría la opción por vivir en el campo. En este contexto, para estos nuevos pobladores, los escenarios rurales de acogida representarían un campo abierto y lleno de posibilidades para la práctica altruista o filantrópica.

Más allá de restringir su acción a lo preciso o mínimo que les corresponde (prestar asistencia técnica agroproductiva, establecer planes de manejo ambiental, escolarizar a los niños y jóvenes rurales, entre los compromisos adquiridos con las instituciones contratantes), como factor común, su labor se extiende, por su cuenta, a otras acciones por ellos valoradas importantes: elevar los niveles de autoestima de la gente, valorizar de manera positiva lo que significa ser campesino y/o agricultor familiar, ayudar a que los propios originarios del campo descubran y desaten sus potencialidades, en medio de un contexto social generalmente hostil. Sumado a lo anterior, en respuesta a su autoafirmación como miembros de las comunidades rurales de acogida, los neorrurales altruistas suelen asumir otros papeles como el de gestores de recursos, asesores y consultores para la toma de decisiones de asuntos comunitarios trascendentes, así como el de expositores o defensores de los intereses locales frente a entidades gubernamentales y no gubernamentales.

Sustentado en lo arriba expuesto, podría plantearse que para estos neorrurales el contexto rural también representaría un espacio de "subversión personal" (HALFACREE, 2007). Para la mayoría de los entrevistados, alejarse de un mercado de trabajo en donde domina el interés por maximizar las remuneraciones recibidas, significa un cambio en respuesta a sus valores y convicciones acerca de su responsabilidad social como expertos en cualquier área profesional. Recurriendo a la clasificación presentada por Iglesia (2005) acerca de lo que incentiva a los profesionales a ejercer su oficio, la motivación de estos neorrurales sería de tipo excéntrico, por cuanto va más allá del interés particular 
del sujeto, pretendiendo conseguir beneficios para otras personas, aun a costa de renunciar a incentivos económicos y de reconocimiento social superiores a los recibidos en las localidades receptoras.

Como referente de distinción o diferenciación social, estos neorrurales se muestran críticos de la actitud asumida por otros profesionales, generalmente actores pertenecientes a la burocracia pública inducida por las políticas de bienestar (sanidad, educación, servicios sociales), que optan por laborar en zonas rurales porque "no encuentran trabajo en otra parte" o porque "son nombrados como cuotas políticas", y para quienes, de acuerdo con su apreciación, "trabajar en el campo representa casi un castigo o sacrificio a soportar temporalmente". Exponen entonces que el nivel de implicación de estos profesionales es bajo, que muchas veces están de paso y ocupan sus cargos de forma provisional (hasta encontrar otra opción trabajo, en lo posible en la ciudad), sumado a que, aun trabajando en zonas rurales alejadas, no habitan en ellas ni muestran disposición para hacerlo.

En síntesis, la manera de vivenciar e integrarse a la dinámica rural característica de este tipo de neorrurales, constituye una forma de resistencia a la dinámica social productivista-economicista dominante, fundamentada en el individualismo, el ánimo de lucro y la búsqueda de poder económico y político. En este caso, el compromiso con la gente del sitio de acogida va más allá de una simple obligación contractual, constituyendo para ellos, sobre todo, una forma de realización personal afín a sus ideales y maneras de leer el mundo.

\subsection{Neorrurales por atracción económico-productiva}

Personas y grupos para quienes la opción por salir de la ciudad e instalarse del todo en el campo responde a una intención u oportunidad económica, esta vez asociada a la producción agropecuaria (actividades agrícolas, pecuarias, piscícolas, agroforestales o agrocomerciales) o a la prestación de múltiples servicios dirigidos a una población mayoritariamente urbana, ofertas derivadasdelarevalorización delosespaciosrurales y al otorgamiento de otras funciones distintas a la tradicional agrícola: funciones patrimoniales (ambientales, culturales, paisajísticas), de esparcimiento y ocio, principalmente.

Para estos neorrurales, el espacio rural correspondería a un espacio productivo o de oportunidades productivas, apto para llevar a cabo ideas de negocio o inversión, generalmente bajo la figura de microempresa o negocio familiar.

Entre los destacados en la zona de estudio encontramos profesionales en ciencias agropecuarias (recién egresados, en su mayoría), administradores de empresas, ingenieros de alimentos y agroindustriales, que ven en el campo posibilidades de inversión y ejercicio profesional, actores para quienes la actividad realizada en el espacio rural constituye una de las principales fuentes de renta familiar. Dada las características de las actividades ejercidas, para estos nuevos habitantes del campo, la movilidad entre el campo y la ciudad es permanente, sobre todo en atención a la venta de productos agrícolas, la provisión de insumos y la oferta publicitaria de los servicios ambientales o recreativos prestados.

Los neorrurales por atracción económicaproductiva se pueden subdividir en:

\subsubsection{Neorrurales agroexpertos}

Personas y grupos cuyo interés consiste en desarrollar en los espacios rurales de acogida, sitios usualmente elegidos de acuerdo con las características agroclimáticas y otras ventajas comparativas, proyectos productivos agrícolas o pecuarios, haciendo uso de su experticia agronómica y/o zootécnica, principalmente. Se trata de profesionales en ciencias agropecuarias, por lo general de origen citadino, sin ninguna experiencia en la producción primaria y poco conocimiento vivencial sobre la dinámica socioeconómica rural previa a su formación profesional, quienes después de titulados optan por radicarse en zonas rurales, bien sea 
comprando o arrendando predios, con el fin de desarrollar iniciativas productivas, estableciendo allí su sitio de habitación permanente.

Podría decirse que, para estos nuevos habitantes del campo, sus proyectos de vida en el espacio rural se fundamentarían en realizarse como productores agrícolas exitosos, con capacidad de insertarse a los mercados locales y regionales, asumiendo como premisa orientadora que "para producir en el campo es necesario vivir en el campo", expresión reiterativamente usada por los entrevistados.

En este marco, vivir en el campo supondría primordialmente estar comprometidos con el constante aumento de la productividad, la expansión del negocio y la maximización del lucro (BURTON, 2004), haciendo uso del conocimiento técnico, tecnológico y científico como medida para optimizar la inversión de capital de acuerdo con las exigencias del negocio agropecuario. En este sentido, el medio rural sería asumido como un espacio socioproductivo administrable, planificable y gerenciable, de acuerdo con los objetivos propuestos, y "ser rural" (como referente de identidad) significaría actuar como agente productivo dentro de la dinámica socioeconómica del sitio de acogida.

En síntesis, para estos neorrurales, la experiencia rural de vida se asimilaría a la vivencia directa, cotidiana y hasta rutinaria de un proceso de producción agrícola y/o pecuaria sostenido en el tiempo, en donde la unidad productiva y la doméstica-familiar se cruzarían sin llegar a convertirse en una sola.

En este caso, vivir con la familia en el campo permitiría combinar en un mismo escenario actividades de índole reproductiva y productiva, siendo esta última usualmente asumida por uno de los jefes de familia (esposo o esposa, casi siempre), actor que posee el conocimiento científico y el entrenamiento técnico para hacerlo. Se trata de actividades especializadas a cuya realización no contribuyen, de manera obligatoria, los otros miembros del hogar. A pesar de vivir en el predio rural (unidad a su vez habitacional y productiva), estos últimos pueden estudiar o trabajar en zonas urbanas aledañas, bajo un esquema de movilidad diaria entre el campo y la ciudad, manteniendo o no lazos individuales con la actividad agroproductiva. En caso de la elección formativa, estudiar o no una carrera agropecuaria, interesarse o no por dar continuidad al negocio en un inicio proyectado como familiar, daría cuenta de lo dicho.

Dada esta situación, aunque debido en buen grado a las demandas del mismo negocio agrícola, los neorrurales a cargo de estos emprendimientos recurren al trabajo asalariado, hecho que genera oportunidades de empleo, sobre todo entre la gente que vive en las inmediaciones del predio, siendo esta una forma de integración social funcional entre ellos y sus congéneres nativos, interacción fundamentada en relaciones contractuales.

\subsubsection{Neorrurales innovadores}

Personas y grupos cuyo interés consiste en desarrollar en los espacios rurales de acogida, propuestas innovadoras de negocio distintas a las tradicionalmente agrícolas. Se trata de individuos que invierten en proyectos identificados como económica y financieramente viables, de acuerdo con las indicaciones del mercado y las tendencias contemporáneas de consumo. En términos generales, se trata de iniciativas asociadas al turismo rural (agro y ecoturismo, principalmente), que tienen como público a visitantes provenientes de entornos urbanos, para quienes el campo constituye una fuente de deleite estético, psíquico y recreativo, figuración asumida por este tipo de neorrurales como oportunidad comercial. Para ellos, estar al frente de sus emprendimientos, atendiendo personalmente a los clientes de sus hoteles y posadas rurales, restaurantes, parques temáticos y granjas interactivas, entre los negocios más reconocidos en la zona de estudio, justifica su permanencia en el campo y la ubicación allí de su sitio de residencia principal. 
En este contexto, sobre una perspectiva ocupacional y rentística, podría anotarse que, para ellos, el espacio rural representaría un escenario de inversión en potencia, donde el paisaje agrícola, conjugado con el espacio natural y cultural circundante, se convierte en recurso económicamente aprovechable. Bajo esta óptica, ahora significado como naturaleza y cultura, lo rural pasaría a ser visto como lugar para el ejercicio de otro tipo de trabajo, no más limitado a la producción de alimentos y materias primas para la industria, mas sí abierto a la producción de bienes simbólicos que alimentan la industria cultural.

A estos neorrurales, incorporarse al medio rural con la intención de prestar servicios de recreo y esparcimiento les implica, además de adquirir habilidades gerenciales y de marketing específicas, hacerse conocedores de las singularidades de la localidad receptora, siendo esta una forma de integrarse a la dinámica social del lugar, a partir de la necesaria interacción con los actores originarios del campo que poseen ese conocimiento. La historia, la cultura, las tradiciones, las celebraciones y fiestas populares, las faenas agrícolas más representativas, los bienes arquitectónicos, la culinaria y las atracciones naturales de la región, entre otros elementos, hacen parte de ese acervo cultural y natural que estos nuevos habitantes del campo necesitan apropiar y conocer. Se trata de aprendizajes hechos en respuesta a las demandas de un público visitante extremadamente cuestionador y curioso, para quienes el medio rural no deja de causar asombro.

En esta línea, establecer alianzas con los originarios del campo, es decir, con los conocedores in situ de los distintos aspectos de las áreas rurales de influencia, que puede lograrse a partir de relaciones contractuales (bien sea de tipo informal o formal), constituye una forma de integrarse a la dinámica socioeconómica y cultural local, hecho mediado más por el interés comercial, que por el ánimo de generar condiciones inclusivas de desarrollo o bienestar social en el espacio de acogida.

\subsection{Neorrurales por expulsión}

Personas y grupos para quienes la decisión de trasladarse a y vivir permanentemente en el campo constituye, en principio, una estrategia de evitación o huida de situaciones peligrosas, intolerables, molestas o perjudiciales, experimentadas en los contextos urbanos de procedencia. Desde esta perspectiva, el espacio rural correspondería a un espacio de refugio al que se recurre, bien sea de forma individual o colectiva, como medio de evasión de situaciones indeseables que generan vulnerabilidad, inequidad, pobreza y otros efectos negativos en las distintas dimensiones de la vida, poniendo en riesgo la capacidad de subsistencia, la dignidad de las personas y las comunidades, incluyendo amenazas sobre la propia vida o la de otros miembros del hogar.

Para estos neorrurales, la búsqueda de seguridad vista más allá de la ausencia de violencia, es decir, ampliada a otras amenazas que recaen sobre los seres humanos (desempleo, inseguridad alimentaria, problemas de salud, desastres naturales, entre lo más evidenciado en campo), se ve realizada a partir del establecimiento en escenarios rurales por ellos mismos considerados "sanos" y "tranquilos para vivir", acto al que prosiguen procesos de adaptación a las dinámicas sociales de los sitios de acogida.

En términos generales, se trata de obreros de la construcción, empleados domésticos, vendedores ambulantes, dueños de pequeños establecimientos comerciales, transportadores (conductores de vehículos de servicio público), profesores (usualmente de instituciones de educación básica primaria), entre otros actores que ejercían sus oficios en el contexto urbano de expulsión, que al instalarse en el campo continúan realizando a tiempo completo o parcial esas mismas actividades, combinándolas, cuando viene al caso, con labores agropecuarias, si es que esta no se convierte en actividad principal. Como factor común, son individuos con ingresos y niveles de escolaridad bajos, provenientes de barrios populares de ciudades grandes e 
S044 - Una Tipología de los Nuevos Habitantes del Campo: aportes para el estudio del fenómeno neorrural a partir del caso de Manizales, Colombia

intermedias. Los neorrurales por expulsión se pueden subdividir en:

\subsubsection{Neorrurales desplazados}

Personas y grupos de origen citadino que, al verse atrapados en círculos de violencia propios de las localidades (barrios o comunas) en las que vivían en la ciudad, optan por soslayar las situaciones de conflicto, buscando resguardo en áreas rurales cercanas o distantes. Para ellos, constituir un proyecto de vida en el campo, representa una forma de evitar "llevar una mala vida", idea asociada a la vivencia urbana en un contexto dominado por las economías ilegales, la producción y la comercialización de narcóticos, el tráfico de armas y la lucha por la apropiación del territorio por parte de distintos grupos en disputa, circunstancias que en conjunto ponen en entredicho la sobrevivencia de la gente.

En general, se trata de circunstancias no sólo experimentadas en las zonas rurales, sino también hoy con más fuerza evidenciadas en algunos sectores de ciudades grandes e intermedias, que crean otras formas de desplazamiento como la direccionada de la ciudad al campo. Es un tipo de migración poco evidenciado o estudiado, sobre todo en contextos como el colombiano en donde el conflicto armado hoy se asienta en áreas, regiones y poblados rurales, sin que esto quiera decir que esté presente en la totalidad ellos. De ahí que cuando se decide migrar de la ciudad al campo, generalmente se buscan sitios de acogida en lo posible libres de este tipo de conflictos o donde al menos sean de baja intensidad.

Para este tipo de neorrurales, el sitio rural de acogida representa un espacio de refugio y evitación de situaciones indeseables vivenciadas en el contexto urbano de salida, en circunstancia en que esos espacios rurales son por ellos mismos valorados como "sanos" y "tranquilos".

Respecto al proceso de adaptación al nuevo contexto rural de vida, el estigma de venir de la ciudad suele acompañar a estos neorrurales en un primer momento, hecho agravado por la procedencia de escenarios urbanos violentos. Es un estigma superable casi siempre a partir de la inmersión positiva posibilitada por las familias que usualmente los acogen y que en principio asumen su tutela. Sin descartar el rechazo o prevención inicial, la tutela asumida por las familias hospedantes genera mayores sentimientos de aceptación y confianza por parte de los otros hacia ellos, facilitando su más rápida articulación a las dinámicas sociocomunitarias locales. En este escenario de inmersión y adaptación, el desplazamiento algunas veces asumido como una cuestión temporal, se convierte poco a poco en un cambio definitivo del proyecto de vida individual y familiar.

En cuanto a su adaptación para estos nuevos habitantes del campola convivencia en un entorno familiar agrícola supone involucrarse con esta actividad primaria, aprendiendo y ejecutando las labores propias de los sistemas productivos prevalecientes en el espacio de acogida. Por su parte, los conocimientos, habilidades y saberes precedentes, es decir, los ejercidos en la ciudad, continúan siendo usados en el nuevo entorno como constitutivos parciales de sus estrategias de reproducción socioeconómica. Esta conjunción de actividades agrícolas y no agrícolas da lugar a la instauración de modelos productivos reproductivos pluriactivos, en donde ambos aprendizajes resultantes de la estancia en el campo y la ciudad incrementan la capacidad de la gente para adecuarse al nuevo contexto de vida (MÉNDEZ, 2011).

En relación con lo no agrícola, prestar servicios afines a las necesidades, demandas y deseos de los habitantes del campo (servicios de construcción y mantenimiento locativo, venta de productos por catálogo, tiendas y bares, minimercados vecinales en los que venden artículos de consumo básico, incluyendo alimentos y algunos insumos agrícolas) constituye una de las principales ocupaciones. En este caso, la habilidad para ver a sus congéneres rurales no sólo como productores agrícolas sino también como consumidores de toda una serie de bienes y servicios favorece esta forma de adaptación. Por su parte, dicha incursión en lo ocupacional no agrícola, vía imitación o 
integración, llega a extenderse a los núcleos familiares de acogida, instaurando, incentivando o reforzando en éstos la adopción de modelos ocupacionales pluriactivos. Analíticamente, se trata de hecho que parcialmente revela la influencia de estos neorrurales sobre las dinámicas socioeconómicas locales.

Como cierre vale destacar que la adaptación de los neorrurales desplazado al nuevo entorno de vida es un proceso gradual que demanda tiempo y convencimiento acerca de la decisión tomada. Para ello, el papel de las redes de solidaridad (bien sea familiares o comunitarias), que en un principio les ayudan a suplir ciertas necesidades inmediatas (residencia y alimentación principalmente), hasta que logren cierta autonomía, juegan un papel destacado.

\subsubsection{Neorrurales recalificados}

Personas y grupos de origen citadino que, principalmente por motivos económicos, voluntariamente optan por trasladar al campo en procura de nuevas y más beneficiosas alternativas generadoras de ingresos, decisión en términos generales asumida como mecanismo contra el desempleo, a fin de garantizar la subsistencia cuando se ven afectados por la desocupación involuntaria. En este caso, se trata de individuos y familias en las que la decisión de migrar al campo se toma en el marco de una situación no extrema (como quienes migran debido a la presión del conflicto armado), manteniendo la esperanza de que el nuevo proyecto les proporcione unas condiciones de vida y empleabilidad que sean, sino mejores, por lo menos un tanto más cómodas en comparación con las que han dejado.

Tratándose de un proceso migratorio estimulado por motivos económicos, la decisión de residir de manera permanente en el campo les exige reformar drásticamente su perfil profesional, procurándose de nuevos conocimientos, habilidades y destrezas afines a la vocación casi siempre agropecuaria de los espacios rurales de acogida. De ser obreros de la construcción, empleados domésticos, vendedores ambulantes informales, dependientes de establecimientos comerciales de diferente índole, entre otras ocupaciones, pasan a ser trabajadores agrícolas o cuidadores de predios productivos y/o recreativos, siendo esta última opción la que más brinda la oportunidad de ofrecer a la familia un lugar de residencia en el mismo predio.

Para estos neorrurales, el espacio físicosocial rural representaría un escenario de oportunidades en potencia en donde se aspira a superar inconvenientes de índole económica, agravados y poco superables en el medio urbano de salida. En este caso, aprovechar las oportunidades brindadas en los espacios rurales de acogida les implica entrar en un proceso de reconversión o recualificación profesional para el ejercicio de las labores requeridas por los sistemas de producción agropecuaria allí predominantes.

A este fin, las redes familiares y de amistad juegan un papel primordial en relación con dos asuntos clave: i) la visualización del espacio rural como oferente de oportunidades laborales (casi siempre de subsistencia), y ii) la adquisición de competencias básicas para responder a las ofertas ocupacionales rurales, considerando que para los nuevos habitantes pueden constituir una completa novedad. Para el caso en estudio, activando y haciendo uso de red de relaciones preexistentes, en épocas de cosecha, cuando la demanda de mano de obra es alta, algunos habitantes originarios del campo convocan a amigos y parientes citadinos a experimentar como trabajadores agrícolas, facilitándoles la estadía y el entrenamiento para el desempeño de las labores requeridas. Esta primera aproximación al campo y a las faenas agrícolas, sumada a la percepción positiva de la vida cotidiana de sus congéneres rurales (exploración de cómo viven, cuánto ganan, a qué dedican su tiempo, de qué obtiene sus ingresos, dónde estudian sus hijos, cómo acceden a una vivienda, qué oportunidades y restricciones persisten en el desarrollo de la vida diaria, entre otros asuntos) llega a constituir el estímulo inicial para optar por quedarse en el campo.

En esta vía, una vez instalados en el espacio rural de acogida, cualificarse como agricultores, 
generalmente dejando a un lado u otorgándole menor protagonismo a las actividades habitualmente ejercidas en las localidades urbanas de expulsión, constituye para ellos el camino a seguir. Para estos neorrurales, adquirir habilidades y competencias que los capacite para mantener el empleo o encontrar uno nuevo en el mismo ámbito rural -retomando lo expuesto por Rentería y Malvezzi, 2008- haría parte de sus maniobras de inclusión en el mercado de trabajo disponible. En estos términos, mejorar el nivel de empleabilidad sería una estrategia destinada a mejorar y perfeccionar el tránsito entre el desempleo urbano y el empleo rural/agrícola.

En estecaso, acceder a los recursos productivos generalmente brindados por las unidades locales o regionales de asistencia técnica y otras agencias estatales de capacitación constituye la vía de cualificación y profesionalización agropecuaria esta oferta parcialmente garantiza el acceso a algunos insumos productivos y a la capacitación en temas de interés y utilidad como manejo y cuidado de especies menores, granja integral, mantenimiento de huertas, transformación primaria y procesamiento de alimentos, por ejemplo). Para estos nuevos habitantes del campo, incorporarse a la dinámica local (a una nueva cultura y un nuevo estilo de vida) implica habilitarse para desarrollar actividades acordes con las posibilidades del medio, necesidad donde se enmarca su reconocimiento como actores de procedencia urbana reformados.

En síntesis, esta tipología da cuenta de la diversidad local existente y resulta para contextualizar el hecho migratorio y establecer distanciamientos y similitudes en la expresión del fenómeno neorrural, en relación con formas particulares de ocurrencia en otros escenarios bien sea física o socialmente próximos o apartados. Como expusimos, puede afirmarse que la decisión de migrar hacia áreas rurales tomada por ciertos pobladores urbanos obedece no sólo a la búsqueda de belleza paisajística o de escape a la contaminación ambiental urbana, por ejemplo, sino también a asuntos de orden político/ideológico, comercial, productivo y a la búsqueda de seguridad en diferentes sentidos. Por otra parte, la idea aventajada acerca de que los neorrurales son mayoritariamente sujetos de clase media acomodada, es atenuada en la medida que actores identificables como de bajo nivel de renta también entran en escena, hecho que igualmente apunta al reconocimiento de la diversidad aludida.

A manera de cierre, es también pertinente considerar que la propuesta de tipos presentada no se explica únicamente por las circunstancias locales, sino que, en términos generales, representan un testimonio dinámico y multidimensional de los procesos y situaciones observables en las sociedades rurales latinoamericanas de hoy.

\section{Consideraciones finales}

En contextos más próximos a los nuestros, como sería el caso de la mayor parte de América Latina, hablar de "nuevas ruralidades", incluyendo el tema de los "neorrurales", causa, por lo menos en algunos, cierta inconformidad intelectual. Como argumenta González (2004), dicho fenómeno suele ser más concebido como una realidad del "Norte" que como un asunto generalizado o de importancia en el "Sur", donde problemas de orden estructural e históricamente no resueltos (redistribución de activos productivos, pobreza, institucionalidad para el desarrollo, inequidad de género, por ejemplo) deberían ocupar la atención de los estudiosos e investigadores de la cuestión rural. Para los críticos de este tipo de estudios, fenómenos como el neorrural estarían más relacionados con lo experimentado en sociedades postindustriales, que con aquellas que apenas presentan un decorado "postmoderno" (un mundo rural agroindustrial, menos agrícola y más turístico, menos material y más abstracto, por ejemplo), soportado en una realidad premoderna, en la que prima la marginalidad social, económica y cultural.

No obstante, como fue desarrollado en esta investigación, a esas aristas problemáticas donde 
prima la sobreexplotación, el desplazamiento, la violencia, la desigualdad social, entre otros elementos, se suman otras de menor expresión, mas no por eso menos significativas, en las que el mundo rural se disfruta, recupera, apropia y modifica desde diferentes perspectivas. Son hechos que se alejan de la media y que sin embargo están ahí presente, haciendo parte de la ruralidad contemporánea y dando fe de la emergencia de nuevos actores rurales. En este sentido, resulta útil recordar que el mundo rural es lo bastante grande para dar cabida a esos otros actores y que no hay ninguna prioridad lógica para centrar el interés en apenas un grupo de sujetos desvalorizando o invisibilizando la presencia de otros, consideración que habría de guiar a quienes tienen el propósito de estudiar y comprender las sociedades rurales en su diversidad y constante transformación.

Asociado a esto último, es preciso afirmar que los fenómenos migratorios, como el aquí investigado, noúnicamente expresan movimientos de población de un lado a otro, sino que también darían cuenta de lo que está aconteciendo en una sociedad específica (Gómez, 2008). Para el caso de estudio, la emergencia de nuevos habitantes del campo (y, en términos generales, la presencia de procesos migratorios que van de lo urbano a lo rural) daría cuenta de circunstancias hoy más que nunca vigentes como: la revalorización de lo rural como espacio alternativo de vida, la búsqueda de válvulas de escape por parte de pobladores urbanos al modo de vida citadino, la multifuncional y creciente articulación entre escenarios físico-sociales urbanos y rurales, la ambientalización de lo rural y el aprovechamiento económico de ello, la violencia y degradación social contemporánea urbana, y la aparición de iniciativas, aún emergentes, de intentos de resarcimiento de la deuda histórica de la sociedad en general con los más vulnerables del campo.

Por último, vale considerar que cuando se hace referencia al mundo rural, es preciso ubicarse ante una realidad imprevisible en su mutabilidad, pero a la vez constantemente moldeada por múltiples prácticas constructoras de sentido, como las realizadas por los protagonistas de esta investigación.

\section{Referencias bibliográficas}

BURTON, R. Seeing through the good farmer's eyes: towards developing and understand of social symbolic value of productivist behavior. Sociologia Ruralis, Oxford, v. 44, n. 2. p. 195-215, 2007.

DE PAULA, S. Natureza, ruralidade e experiência urbana. En: MOREIRA, R. (org.), Identidades sociais. Ruralidades no Brasil contemporâneo Rio de Janeiro: DP\&A Editora, 2005. p. 237-253.

FERNÁNDEZ, G. 2009. La realización de los status de indígena y campesino. Revista Ensemble, París, v. 4, n. 1, 2009. Disponible en: <http://ensemble.educ. $\operatorname{ar} / ? \mathrm{p}=9$ \&numero=7>. Acceso en: 13 de sep. de 2012.

GÓMEZ,C.Comportamientos y relaciones en el espacio rural y su evolución. En: Simposio de Cooperativismo y Desarrollo Rural, 21, 2008, Morillo de Tou. Resúmenes... Morillo de Tou: Centro de Estudios para el Desarrollo Sostenible/Asociación de Estudios Cooperativos, 2008.

GONZALEZ, Y. Óxido de lugar: ruralidades, juventudes e identidades. Nómadas, Bogotá, n. 20, p. 194-209, 2004.

GRIZE, J. Logique naturelle et représentations sociales. En: JODELET, D. (org.), Les représentations sociales. Paris: PUF, 1989. p. 152-168.

HALFACREE, K. Trial by space a radical rural: Introducing alternative localities, representations and lives. Journal of Rural Studies, Londres, v. 23, n. 2, p. 125-141, 2007.

IGLESIAS, J. La carrera profesional en el marco de un sistema de incentivos. Revista JANO, Barcelona, v. 68, n. 1558, p. 17-21, 2005.

JODELET, D. Place de l'expérience vécue dans les processus de formation des représentations sociales. En: HAAS, V. (comp.), Les savoirs du quotidien. Paris: PUR, 2006.

KAYSER, B. Ils ont choisi la campagne. Paris: Editions de l'Aube, 1996.188 p.

MÉNDEZ, M. Incursión ocupacional en escenarios no agrícolas: tendencias y desafíos. En: DE GRAMMONT, H. y MARTÍNEZ, L (comps.), La pluriactividad en el campo latinoamericano. Quito: FLACSO-Ecuador. 2011. p. 127-144.

URRY, J. La mirada del turista. Lima: Universidad de San Martín de Porres, 2004. 204 p.

OBERAI, J. Migración, urbanización y desarrollo. Roma: OIT, $1989.75 \mathrm{p}$. 
S048 - Una Tipología de los Nuevos Habitantes del Campo: aportes para el estudio del fenómeno neorrural a partir del caso de Manizales, Colombia

OLIVA, J. y CAMARERO, L. Paisajes sociales y metáforas del lugar. Pamplona: Universidad Pública de Navarra, 2005. 164 p.

OLIVEIRA, O. y STERN, C. Notas acerca de la teoría de las migraciones internas: aspectos sociológicos. Buenos Aires: CLACSO, 1972. 29 p.
PALACIO, M. y CIFUENTES, M. El departamento de Caldas: su configuración como territorio de conflicto armado y desplazamiento forzado. Trabajo Social, Bogotá, n. 7, p. 99-110, 2005.

RENTERÍA, E. y MALVEZZI, S. Empleabilidad, cambios $\mathrm{y}$ exigencias psicosociales en el trabajo. Universitas Psychologica, Bogotá, v. 7, n. 2, p. 319-334, 2008. 